\title{
On the best proximity point for the proximal contractive and nonexpansive mappings on the starshaped sets
}

\author{
Meifang Guo ${ }^{1}, \mathrm{Xia}_{\mathrm{Li}}{ }^{1}$ and Yongfu Su${ }^{2^{*}}$ (D)
}

*Correspondence:
tjsuyongfu@163.com
2 Department
of Mathematics, Tianjin
Polytechnic University,
Tianjin 300387, People's
Republic of China
Full list of author information
is available at the end of the
article

*Correspondence:

tjsuyongfu@163.com

of Mathematics, Tianjin

Polytechnic University,

article

\begin{abstract}
The purpose of this paper is to the best proximity point theorems for the proximal nonexpansive mapping on the starshaped sets by using a clever and simple method. The results improve and extend the recent results of Chen et al. (Fixed Point Theory Appl 2015:19, 2015). It should be noted that, the complex method is used by Jianren Chen et al. can be replaced by the clever and simple method presented in this paper.
\end{abstract}

Keywords: Best proximity point, Proximal nonexpansive mapping, Starshaped set, Nonexpansive map

\section{Introduction and preliminaries}

The best proximity point problems and best proximity point theorems are basic part of nonlinear analysis and applications. In the recent years, many authors are studying the best proximity point problems. a lot of the best proximity point theorems and relatively results have been obtained in the metric spaces or normed spaces (see Fan 1969; Reich 1978; Prolla 1983; Sehgal and Singh 1988, 1989; Vetrivel et al. 1992; Basha 2000, 2011a, b; Kirk et al. 2003; Veeramani et al. 2005; Eldred and Veeramani 2006; Gabeleh 2013a, b, 2014; Sankar Raj 2011; Abkar and Gabeleh 2013a, b; Kosuru and Veeramani 2011; Lovaglia 1955; Opial 1967; Al-Thagafi and Shahzad 2009; Zhang et al. 2013; Chen et al. 2015; Hussain and Hezarjaribi 2016; Shayanpour et al. 2016; Yongfu and Yao 2015; AlNemer et al. 2016; Samet 2015; Yongfu et al. 2015; Kiran et al. 2015; Binayak 2015; Kong et al. 2015; Yongfu and Zhang 2014; Sun et al. 2014).

Let $T: A \rightarrow B$, where $A, B$ are two nonempty subsets of a metric space $(X, d)$. Note that if $A \cap B=\emptyset$, the equation $T x=x$ might have no solution. Under this circumstance it is meaningful to find a point $x \in A$ such that $d(x, T x)$ is minimum. Essentially, if $d(x, T x)=\operatorname{dist}(A, B)=\inf \{d(x, y): x \in A, y \in B\}, d(x, T x)$ is the global minimum value $\operatorname{dist}(A, B)$ and hence $x$ is an approximate solution of the equation $T x=x$ with the least possible error. Such a solution is known as a best proximity point of the mapping $T$. A point $x \in A$ is called the best proximity point of $T$ if

$$
d(x, T x)=\operatorname{dist}(A, B)=\inf \{d(x, y): x \in A, y \in B\} .
$$

(c) 2016 Guo et al. This article is distributed under the terms of the Creative Commons Attribution 4.0 International License (http:// creativecommons.org/licenses/by/4.0/, which permits unrestricted use, distribution, and reproduction in any medium, provided you give appropriate credit to the original author(s) and the source, provide a link to the Creative Commons license, and indicate if changes were made. 
It is easy to see that if $A \cap B \neq \emptyset$, the best proximity point just is the fixed point of $T$. We can find an early classical work in Fan (1969), and afterward, there have been many interesting results such as in Reich (1978), Prolla (1983), Sehgal and Singh (1988, 1989), Vetrivel et al. (1992), Basha (2000, 2011a, b), Kirk et al. (2003), Veeramani et al. (2005) and Eldred and Veeramani (2006), and many others ( for example Gabeleh 2013a, b, 2014; Sankar Raj 2011; Abkar and Gabeleh 2013a, b; Kosuru and Veeramani 2011; Lovaglia 1955; Opial 1967; Al-Thagafi and Shahzad 2009; Zhang et al. 2013; Chen et al. 2015; Hussain and Hezarjaribi 2016; Shayanpour et al. 2016; Yongfu and Yao 2015; AlNemer et al. 2016; Samet 2015; Yongfu et al. 2015; Kiran et al. 2015; Binayak 2015; Kong et al. 2015; Yongfu and Zhang 2014; Sun et al. 2014).

Recently, Gabeleh introduced a new notion which is called the proximal nonexpansive mapping in Gabeleh (2013).

Definition 1 (Gabeleh 2013a) Let $(A, B)$ be a pair of nonempty subsets of a metric space $(X, d)$. A mapping $T: A \rightarrow B$ is said to be proximal nonexpansive if

$$
\left\{\begin{array}{l}
d\left(u_{1}, T x_{1}\right)=\operatorname{dist}(A, B) \\
d\left(u_{2}, T x_{2}\right)=\operatorname{dist}(A, B)
\end{array} \Rightarrow d\left(u_{1}, u_{2}\right) \leq d\left(x_{1}, x_{2}\right) .\right.
$$

for all $x_{1}, x_{2}, u_{1}, u_{2} \in A$.

Definition 2 (Basha 2011a) Let $(A, B)$ be a pair of nonempty subsets of a metric space $(X, d)$. A mapping $T: A \rightarrow B$ is said to be proximal contraction if there exists a constant $0<\alpha<1$ such that

$$
\left\{\begin{array}{l}
d\left(u_{1}, T x_{1}\right)=\operatorname{dist}(A, B) \\
d\left(u_{2}, T x_{2}\right)=\operatorname{dist}(A, B)
\end{array} \Rightarrow d\left(u_{1}, u_{2}\right) \leq \alpha d\left(x_{1}, x_{2}\right) .\right.
$$

for all $x_{1}, x_{2}, u_{1}, u_{2} \in A$.

Definition 3 (Kosuru and Veeramani 2011) Let $(A, B)$ be a pair of nonempty subsets of a metric space $(X, d)$. The pair $(A, B)$ is said to be a semi-sharp proximinal pair if for each $x \in A$ (respectively, in $B$ ) there exists at most one $x^{*} \in B$ (respectively, in $A$ ) such that $d\left(x, x^{*}\right)=\operatorname{dist}(A, B)$.

The following notions are presented in Chen et al. (2015).

Definition 4 (Chen et al. 2015) A nonempty subset $A$ of a linear space $X$ is called a $p$-starshaped set if there exists a point $p \in A$ such that $\alpha p+(1-\alpha) x \in A$, for all $x \in A$, $\alpha \in[0,1]$, and $p$ is called the center of $A$.

Let $A, B$ be two nonempty subsets of a metric space $(X, d)$. We denote by $A_{0}$ and $B_{0}$ the following sets:

$$
\begin{aligned}
& A_{0}=\{x \in A: d(x, y)=d(A, B) \text { for some } y \in B\} \\
& B_{0}=\{y \in B: d(x, y)=d(A, B) \text { for some } x \in A\}
\end{aligned}
$$

where $d(A, B)=\inf \{d(x, y): x \in A$ and $y \in B\}$. 
Remark 5 (Chen et al. 2015) It is easy to see that in a normed space $(X,\|\cdot\|)$, if $A$ is a $p$-starshaped set and $B$ is a $q$-qstarshaped set and $\|p-q\|=\operatorname{dist}(A, B), A_{0}$ is a $p$-starshaped set, and $B_{0}$ is a $q$-starshaped set, respectively. If both of $A$ and $B$ are closed and $A_{0}$ is nonempty, $A_{0}$ is closed.

The purpose of this paper is to the best proximity point theorems for the proximal nonexpansive mapping on a starshaped sets by using a clever and simple method. The results improve and extend the recent results of Chen et al. (2015). It should be noted that, the complex method is used by Jianren Chen et al. can be replaced by the clever and simple method presented in this paper.

\section{A clever and simple method of proof}

In Chen et al. (2015), authors proved the following conclusion, which plays an important role in the proof of their main results. However, the method used in the proof is relatively complicated. In this section, we will give a clever and simple method of proof.

Conclusion 1 (Chen et al. 2015, Lemma 3.1) Let $(A, B)$ be a pair of nonempty closed subsets of a complete metric space $(X, d)$ and $A_{0}$ be closed and nonempty. Assume that $T: A \rightarrow B$ satisfies the following conditions:

(a) $T$ is a proximal contraction;

(b) $T\left(A_{0}\right) \subset B_{0}$. Then there exists a unique $x^{*} \in A$ such that $d\left(x^{*}, T x^{*}\right)=\operatorname{dist}(A, B)$.

Simple proof For any $x \in A_{0}$, since $T$ is a proximal contraction, if $d\left(u_{1}, T x\right)=\operatorname{dist}(A, B)$ and $d\left(u_{2}, T x\right)=\operatorname{dist}(A, B)$, then $u_{1}=u_{2}$, hence there exists a unique $u \in A_{0}$ such that $d(u, T x)=\operatorname{dist}(A, B)$, we denote by $u=P T x$ this relation. That is, we define a mapping $P$ from $T\left(A_{0}\right)$ into $A_{0}$. Hence $P T$ is a mapping from complete metric subspace $A_{0}$ into itself. From (a) we know that,

$$
d\left(P T x_{1}, P T x_{2}\right) \leq \alpha d\left(x_{1}, x_{2}\right), \forall x_{1}, x_{2} \in A_{0} .
$$

By using Banach contraction mapping principle, there exists a unique point $x^{*} \in A_{0}$ such that $x^{*}=P T x^{*}$, this equivalent to $d\left(x^{*}, T x^{*}\right)=\operatorname{dist}(A, B)$. The proof is completes.

The following conclusion is a main result of Jianren Chen et al. The method used in the proof is also complicated. In this section, we also give a very simple method of proof.

Conclusion 2 (Chen et al. 2015, Theorem 3.3) Let $(A, B)$ be a pair of nonempty, closed subsets of a Banach space $X$ such that $A$ is a p-starshaped set, $B$ is a q-starshaped set, and $\|p-q\|=\operatorname{dist}(A, B)$. Suppose $A$ is compact, and $(A, B)$ is a semi-sharp proximinal pair. Assume that $T: A \rightarrow B$ satisfies the following conditions:

(a) $T$ is a proximal nonexpansive;

(b) $T\left(A_{0}\right) \subset B_{0}$.Then there exists an element $x^{*} \in A$ such that $\left\|x^{*}-T x^{*}\right\|=\operatorname{dist}(A, B)$. 
Simple proof For any $x \in A_{0}$, since $T$ is a proximal nonexpansive, there exists a unique $u \in A_{0}$ such that $d(u, T x)=\operatorname{dist}(A, B)$, we denote by $u=P T x$ this relation. Hence $P T$ is a mapping from complete metric subspace $A_{0}$ into it-self. From (a) we know that,

$$
\left\|P T x_{1}-P T x_{2}\right\| \leq\left\|x_{1}-x_{2}\right\|, \quad \forall x_{1}, x_{2} \in A_{0} .
$$

Hence $P T$ is a nonexpansive mapping from $A_{0}$ into it-self. We define a mapping $S: A_{0} \rightarrow A_{0}$ by

$$
S x=\lambda p+(1-\lambda) P T x
$$

where $0<\lambda<1$, then $S$ is a contraction. From Remark 5 , we know that $A_{0}$ is closed, by using Banach contraction mapping principle, there exists a unique element $x_{\lambda} \in A_{0}$ such that

$$
x_{\lambda}=\lambda p+(1-\lambda) P T x_{\lambda}
$$

for any $0<\lambda<1$. Therefore, there exists a sequence $\left\{x_{n}\right\}$ such that

$$
x_{n}=\frac{1}{n} p+\left(1-\frac{1}{n}\right) P T x_{n}
$$

which implies that

$$
\left\|x_{n}-P T x_{n}\right\|=\left(1-\frac{1}{n}\right)\left\|p-P T x_{n}\right\| \rightarrow 0 .
$$

as $n \rightarrow \infty$, since $A$ is compact. On the other hand, there exists a subsequence $\left\{x_{n_{k}}\right\}$ to converge a element $x^{*} \in A$. Therefore $x^{*}=P T x^{*}$, this is equivalent to $d\left(x^{*}, T x^{*}\right)=\operatorname{dist}(A, B)$. The proof is completes.

\section{Further generalized results}

By using the same method as in the Conclusion 2, we can get the following further generalized results without assume the $(A, B)$ is a semi-sharp proximinal pair, and the $A$ is compact.

Theorem 1 Let $(A, B)$ be a pair of nonempty, closed subsets of a Banach space $X$ such that $A$ is a $p$-starshaped set, $B$ is a $q$-starshaped set, and $\|p-q\|=\operatorname{dist}(A, B)$. Suppose $A$ is weakly compact. Assume that $T: A \rightarrow B$ satisfies the following conditions:

(a) $T$ is a proximal nonexpansive;

(b) $T\left(A_{0}\right) \subset B_{0}$. Then there exists an element $x^{*} \in A$ such that $\left\|x^{*}-T x^{*}\right\|=\operatorname{dist}(A, B)$.

Proof Since $A$ is weak compact, there exists a subsequence $\left\{x_{n_{k}}\right\}$ to converge weakly a element $x^{*} \in A$. Noting that, the nonexpansive mapping $P E$ is demi-closed, then $x^{*}=P T x^{*}$, this is equivalent to $d\left(x^{*}, T x^{*}\right)=\operatorname{dist}(A, B)$. The proof is completes.

Theorem 2 Let $X$ be a uniformly convex Banach space with the Opail's condition. Let $(A, B)$ be a pair of nonempty, closed subsets of $X$ such that $A$ is a p-starshaped set, $B$ is a 
$q$-starshaped set, and $\|p-q\|=\operatorname{dist}(A, B)$. Suppose $A$ is bounded. Assume that $T: A \rightarrow B$ satisfies the following conditions:

(a) $T$ is a proximal nonexpansive;

(b) $T\left(A_{0}\right) \subset B_{0}$. Then there exists an element $x^{*} \in A$ such that $\left\|x^{*}-T x^{*}\right\|=\operatorname{dist}(A, B)$.

Proof Since $A$ is bounded so it is weak compact, there exists a subsequence $\left\{x_{n_{k}}\right\}$ to converge weakly a element $x^{*} \in A$. Noting that, since $X$ satisfies Opail's condition, the nonexpansive mapping $P E$ must be demi-closed (see Lemma 2 in Opial 1967), then $x^{*}=P T x^{*}$, this is equivalent to $d\left(x^{*}, T x^{*}\right)=\operatorname{dist}(A, B)$. The proof is completes.

Let $g: A_{0} \rightarrow A_{0}$ be an isometry, we replace by $S=g^{-1} P T$ the $S=P T$, respectively in Theorems 1 and 2, we can get the following results which are further generalized forms to the result of Chen et al. (2015, Theorem 3.4).

Theorem 3 Let $(A, B)$ be a pair of nonempty, closed subsets of a Banach space X such that $A$ is a $p$-starshaped set, $B$ is a q-starshaped set, and $\|p-q\|=\operatorname{dist}(A, B)$. Suppose $A$ is weakly compact. Assume that $T: A \rightarrow B, g: A_{0} \rightarrow A_{0}$ satisfy the following conditions:

(a) $T$ is a proximal nonexpansive;

(b) $T\left(A_{0}\right) \subset B_{0}$.

(c) $g$ is an isometry.

Then there exists an element $x^{*} \in A$ such that $\left\|g x^{*}-T x^{*}\right\|=\operatorname{dist}(A, B)$.

Theorem 4 Let $X$ be a uniformly convex Banach space with the Opail's condition. Let $(A, B)$ be a pair of nonempty, closed subsets of $X$ such that $A$ is a p-starshaped set, $B$ is a q-starshaped set, and $\|p-q\|=\operatorname{dist}(A, B)$. Suppose $A$ is bounded. Assume that $T: A \rightarrow B, g: A_{0} \rightarrow A_{0}$ satisfy the following conditions:

(a) $T$ is a proximal nonexpansive;

(b) $T\left(A_{0}\right) \subset B_{0}$.

(c) $g$ is an isometry.

Then there exists an element $x^{*} \in A$ such that $\left\|g x^{*}-T x^{*}\right\|=\operatorname{dist}(A, B)$.

Definition 6 (Chen et al. 2015) Let $(A, B)$ be a pair of nonempty subsets of a metric space $(X, d)$. The pair $(A, B)$ is said to have the weak $P$-property if

$$
\left\{\begin{array}{l}
d\left(x_{1}, y_{1}\right)=\operatorname{dist}(A, B) \\
d\left(x_{2}, y_{2}\right)=\operatorname{dist}(A, B)
\end{array} \Rightarrow d\left(x_{1}, x_{2}\right) \leq d\left(y_{1}, y_{2}\right) .\right.
$$

for all $x_{1}, x_{2} \in A_{0}, y_{1}, y_{2} \in B_{0}$.

By using the well-known Schauder fixed point theorem, we can improve the result of (Theorem 4.1, Chen et al. 2015) to the following generalized result.

Theorem 5 Let $(A, B)$ be a pair of nonempty, closed, and convex subsets of a Banach space $X$ such that $A$ is compact. Suppose that $A_{0}$ is nonempty and $(A, B)$ has the weak 
P-property. Let $T: A \rightarrow B$ be a nonexpansive non-self-mapping such that $T\left(A_{0}\right) \subset B_{0}$. Then $T$ has at least one best proximity point in $A$.

Proof In this case, the mapping $P T$ defined in Conclusion 2 is also a nonexpansive mapping from $A_{0}$ into it-self. Since $A$ is compact and convex, by using Schauder fixed point theorem, there exists a element $x^{*} \in A$ such that $x^{*}=P T x^{*}$, this is equivalent to $\left\|x^{*}-T x^{*}\right\|=\operatorname{dist}(A, B)$. This completes the proof.

Authors' contributions

All authors contributed equally and significantly in writing this article. All authors read and approved the final manuscript.

\section{Author details}

${ }^{1}$ Deprtment of Mathematics and Sciences, Shijiazhuang University of Economics, Shijiazhuang 050031, People's Republic of China. ${ }^{2}$ Department of Mathematics, Tianjin Polytechnic University, Tianjin 300387, People's Republic of China.

\section{Competing interests}

The authors declare that they have no competing interests.

Received: 13 November 2015 Accepted: 6 March 2016

Published online: 15 March 2016

\section{References}

Abkar A, Gabeleh M (2013) A note on some best proximity point theorems proved under P-property. Abstr Appl Anal 2013:189567

Abkar A, Gabeleh M (2013) Best proximity points of non-self mappings. Top 21(2):287-295

AlNemer G, Markin J, Shahzad N (2016) On best proximity points of upper semicontinuous multivalued mappings. Fixed Point Theory Appl 2015:237

Al-Thagafi MA, Shahzad N (2009) Convergence and existence results for best proximity points. Nonlinear Anal Theory Methods Appl 70(10):3665-3671

Basha SS (2011a) Best proximity points: optimal solutions. J Optim Theory Appl 151(1):210-216

Basha SS (2011b) Best proximity point theorems. J Approx Theory 163(11):1772-1781

Basha SS, Veeramani P (2000) Best proximity pair theorems for multifunctions with open fibres. J Approx Theory 103(1):119-129

Chen J, Xiao S, Wang H, Deng S (2015) Best proximity point for the proximal nonexpansive mapping on the starshaped sets. Fixed Point Theory Appl 2015:19

Choudhury BS, Metiya N, Postolache M, Konar P (2015) A discussion on best proximity point and coupled best proximity point in partially ordered metric spaces. Fixed Point Theory Appl 2015:170

Eldred AA, Veeramani P (2006) Existence and convergence of best proximity points. J Math Anal Appl 323(2):1001-1006

Fan K (1969) Extensions of two fixed point theorems of F.E. Browder. Math Z 112(3):234-240

Gabeleh M (2013) Proximal weakly contractive and proximal nonexpansive non-self-mappings in metric and Banach spaces. J Optim Theory Appl 158(2):615-625

Gabeleh M (2013) Global optimal solutions of non-self mappings. Sci Bull Politeh Univ Buchar Ser A 75:67-74

Gabeleh M (2014) Best proximity point theorems via proximal non-self mappings. J Optim Theory Appl 164:565-576

Hussain N, Hezarjaribi M, Kutbi MA, Salimi P (2016) Best proximity results for Suzuki and convex type contractions. Fixed Point Theory Appl 2016:14

Kiran Q, Ali M, Kamran T, Karapinar E (2015) Existence of best proximity points for controlled proximal contraction. Fixed Point Theory Appl 2015:207

Kirk WA, Reich S, Veeramani P (2003) Proximinal retracts and best proximity pair theorems. Numer Funct Anal Optim 24(7-8):851-862

Kong D, Liu L, Wu Y (2015) Best proximity point theorems for $\alpha$-nonexpansive mappings in Banach spaces. Fixed Point Theory Appl 2015:159

Kosuru GSR, Veeramani P (2011) A note on existence and convergence of best proximity points for pointwise cyclic contractions. Numer Funct Anal Optim 32(7):821-830

Lovaglia AR (1955) Locally uniformly convex Banach spaces. Trans Am Math Soc 78:225-238

Opial Z (1967) Weak convergence of the sequence of successive approximations for nonexpansive mappings. Bull Am Math Soc 73(4):591-597

Prolla JB (1983) Fixed-point theorems for set-valued mappings and existence of best approximants. Numer Funct Anal Optim 5(4):449-455

Reich S (1978) Approximate selections, best approximations, fixed points, and invariant sets. J Math Anal Appl 62(1):104-113

Samet B (2015) Best proximity point results in partially ordered metric spaces via simulation functions. Fixed Point Theory Appl 2015:232 
Sankar Raj V (2011) A best proximity point theorem for weakly contractive non-self-mappings. Nonlinear Anal Theory Methods Appl 74(14):4804-4808

Sehgal VM, Singh SP (1988) A generalization to multifunctions of Fans best approximation theorem. Proc Am Math Soc 102(3):534-537

Sehgal VM, Singh SP (1989) A theorem on best approximations. Numer Funct Anal Optim 10(1-2):181-184

Shayanpour H, Shams M, Nematizadeh A (2016) Some results on best proximity point on star-shaped sets in probabilistic Banach (Menger) spaces. Fixed Point Theory Appl 2016:13

Su Y, Gao W, Yao J-C (2015) Generalized contraction mapping principle and generalized best proximity point theorems in probabilistic metric spaces. Fixed Point Theory Appl 2015:76

Sun Y, Su Y, Zhang J (2014) A new method for the research of best proximity point theorems of nonlinear mappings. Fixed Point Theory Appl 2014:116

Su Y, Yao J-C (2015) Further generalized contraction mapping principle and best proximity theorem in metric spaces. Fixed Point Theory Appl 2015:120

Su Y, Zhang J (2014) Fixed point and best proximity point theorems for contractions in new class of probabilistic metric spaces. Fixed Point Theory Appl 2014:170

Veeramani P, Kirk WA, Eldred AA (2005) Proximal normal structure and relatively nonexpansive mappings. Stud Math 171(3):283-293

Vetrivel V, Veeramani P, Bhattacharyya P (1992) Some extensions of Fans best approximation theorem. Numer Funct Anal Optim 13(3-4):397-402

Zhang J, Su Y, Cheng Q (2013) A note on A best proximity point theorem for Geraghty-contractions. Fixed Point Theory Appl 2013:99

\section{Submit your manuscript to a SpringerOpen ${ }^{\circ}$ journal and benefit from:}

- Convenient online submission

- Rigorous peer review

- Immediate publication on acceptance

- Open access: articles freely available online

- High visibility within the field

- Retaining the copyright to your article

Submit your next manuscript at $\mathbf{s p r i n g e r o p e n . c o m ~}$ 